\title{
IDENTIFICATION AND MONITORING OF FRESH WATER OUTFLOWS IN COASTAL AREAS: PILOT STUDY ON PSAHNA AREA / EVIA ISLAND - GREECE
}

\author{
Stefouli M. and Tsombos P. \\ I.G.M.E., Mesogion Str.70,115 27, Athens, stefouli@igme.gr, ptsombos@igme.gr
}

\begin{abstract}
Earth systems are interrelated in complex ways, which are inadequately understood. An improved understanding of these systems is necessary in order to develop effective policies for hydrologic management. Furthermore, the results should be communicated to decision-makers.

The aim of the work has been to evaluate the applicability of the use of digital multi-temporal Landsat 5 / 7 images and aerial photography, for the mapping of local scale fresh water outflows, geological features and monitoring changes of the water outflows in coastal areas. "Psahna" map sheet (HAGS, 1977) in the Central part of Evia island in Greece has been used as pilot project area of study. Processing techniques have been applied for the:

- Application of integrated image processing / GIS vector data techniques.

- Image integration and creation of data fusion image products.

- Automatic raster to vector conversion techniques, for the identification of the areal extent of changes in conditions of the water outflows through time and final map updating.

The contribution of the remotely sensed data to the geologic / geomorphologic mapping and identification of changes of fresh water outflow through time is indicated with the processed satellite imagery for the pilot project area. Generally, the use of the remotely sensed images in map updating lies in the fact, that various hydrologic and geologic features can be mapped quickly for large areas while any temporal changes can be identified and evaluated. The satellite data seem to be a cost-effective solution for the map updating procedure. The cost to processing functions is well justifiable to a geologic / hydro-geologic-hydrologic map updating procedure. The system provides monitoring and feedback at appropriate spatial scales, using high resolution satellite remote sensing data and state of the art GIS techniques.
\end{abstract}

\section{INTRODUCTION}

Approximately $70 \%$ of the world's population lives in coastal areas, and the majority of these people depend on coastal aquifers for freshwater. The fragility of these aquifers and their sensitivity to human activity demand informed, competent management to guarantee their survival. Significant knowledge and new technologies related to the subject have accumulated in the last two decades, while a need has emerged for a comprehensive reference that gathers and disseminates crucial information to engineering practitioners and policymakers.

Although not as obvious as river discharge, continental groundwater also discharge directly into the sea. Like surface water, groundwater flows down-gradient. Therefore, groundwater flows directly into the sea wherever a coastal aquifer is connected to the sea. Furthermore, artesian aquifers can extend for considerable distances from shore, underneath the continental shelf with discharge to the sea at their points of outcrop. In some cases, these deeper aquifers may have fractures or other breaches in the overlying confining layers, allowing groundwater to flow into the sea. While the magnitude of such discharge may be relatively minor in areas dominated by river flow, recent studies have indicated that groundwater may occasionally account for a significant fraction of the fresh water inflow (Valiela et al. 1990, Tsombos 1995, Buddemeier 1996, Moore 1996, Tsombos 1999, Astaras et. al., 2002). There are different methods for the measurement of groundwater 
discharge, like seepage meters or the use of geochemical traces. Unfortunately, such methods are very labor-intensive.

Remotely sensed data has proven capability in providing many above surface, surface and sub surface characteristics of land / water units. Synergistic use of remote sensing and ancillary data can be used for the development of the database required for monitoring the status of the environment. GIS can be used to store, process and retrieve the developed database. The use of Landsat and SPOT images in geomorphologic / geologic mapping is well established (Stefouli et al. 2002). However, there is a continuous improvement of the specifications of satellite systems and thus an improvement of the data quality of the image data that are provided to the end user. Remote sensing technology has been also used for several years in marine sciences to measure chlorophyll, water colour, and suspended sediments over large areas. For example, satellite imaging is used for remote estimates of primary production (e.g. Antoine et al. 1996), sea surface temperatures (Schweitzer 1993), sea ice coverage (Garrity 1991, Massom et al. 1999), and coastal change processes (Howarth et al. 1982, Hanslow et al. 1997). Although sensors such as Landsat TM were primarily designed for detecting land features, recent improvements now provide better spatial and spectral resolutions for aquatic studies than previously available. It has also been suggested that remote sensing techniques may be useful for groundwater tracing on land (Uzmann et al. 1989, Batelaan et al. 1998) as well as for the detection of sea springs (Kohout et al. 1973). The idea of using satellite imagery for the detection of SGD is based on anomalies in measurable physical parameters such as sea surface temperature (SST) and turbidity that cause changes in spectral properties. This, in turn causes a change in sea surface radiation (UV, VIS and IR). Due to temperature inertia, groundwater is discharged at different temperatures than that of the sea water column. Temperature and salinity related differences in water density result in discharged water ascending through the water column which creates a positive SST anomaly above sea springs if the discharge rate is high enough. This sea surface temperature anomaly can be localized by mid and far infrared (thermal) channels of colour scanning satellites such as the LANDSAT system. Space borne imagery for sea groundwater discharge would require high resolution images which was not realized on NOAA type satellites (spatial resolution $2.5 \mathrm{~km}$ ) but is now much improved (e.g., LANDSAT 7 has $60 \mathrm{~m}$ spatial resolution in the thermal IR band, $10.40-12.50 \mu \mathrm{m}$ wave length). However, to effectively implement remote sensing into a state environmental monitoring program, there still remain many unanswered questions.

Our objective in this study is to determine if we could use integrated remote sensing / WEB-GIS techniques (http://www. microimages.com/product/ntserver.htm) across the pilot project area for mapping features that are of interest to hydro-geologic research and for monitoring fresh water outflows.

\section{STUDY AREA}

The area defined by Psahna topographic map sheet with the upper left and lower right corner coordinates the $\mathrm{N} 38^{\circ} 49^{\prime} 32^{\prime} \mathrm{E} 23^{\circ} 30^{\prime} 48^{\prime}$ and N $38^{\circ} 29^{\prime} 53^{\prime} \mathrm{E} 23^{\circ} 59^{\prime} 29^{\prime}$ respectively, has been selected as a pilot project area. It is located in the Central part of Evia island, Greece Figure1.

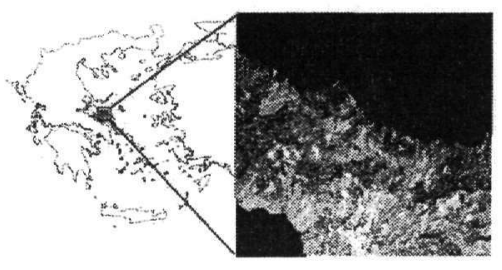

Figure 1. Overview of pilot project study area. 
Karstified limestones, metamorphic and basic ophiolitic rocks are the prevailing lithologies of the study area, while the plains are covered by alluvial and neogene sediments. The central part of Evia island belongs to Pelagonian zone and consists of:

Paleozoic crystallized formations.

Neo-Paleozoic semi-metamorphosed clastic formations.

Formations of Lower-Middle Triassic (clastic formations, volcanic rocks and limestones).

Limestones of Middle - Upper Jurassic.

Masses of ophiolites that are overthrusted on the Upper Cretaceous limestones and

Flysch sediments.

Summer season begins from the end of May continues up to end of September. The temperature variation during summer months is between $18^{\circ} \mathrm{C}$ to $40^{\circ} \mathrm{C}$. During winter it is (-) $5^{\circ} \mathrm{C}$ to $15^{\circ} \mathrm{C}$. Mountains are generally covered by coniferous trees. Ground elevation in the area varies between $0 \mathrm{~m}$ at sea level to $1700 \mathrm{~m}$ above mean sea level. The annual rainfall of Evia island varies from a minimum of about $573.9 \mathrm{~mm}$ for Edipsos meteorological station to $1102.6 \mathrm{~mm}$ for the Milies station. December is the wettest month of the year. Vegetation density is highly variable in spatial and temporal domain. It varies from $0 \%$ to $60 \%$. The soil of the study area is generally coarse grained and aquifers are water table type. Depth of groundwater table varies from about $10 \mathrm{~m}$ to more than $70 \mathrm{~m}$.

\section{ANALYZED DATA}

Synergistic use of, (1) topographic map at 1: 100,000 scale of the Hellenic Geographic Service published at 1977, (2) Psahna-Pilion geologic map at 1: 50,000 (Katsikatsos et. al, 1981), (3) aerial photography of 1:40,000 scale (HAGS, 1967) (4) Landsat TM, images (Figure 2) with variable acquisition dates have been used in the analysis, along with a variety of hydrologic, and meteorological data, as well as field measurements concerning the tectonic features. Synergistic use of remote sensing and conventional techniques has been utilized in order to extract the required data. Field observations of coastal spring data and temperature data were obtained for the pilot project area from a sampling Program that has been carried out during summer 1998. The data have been analyzed along the $114 \mathrm{~km}$ long coastline of the pilot project area that has a surface extent of $1130 \mathrm{~km}^{2}$.

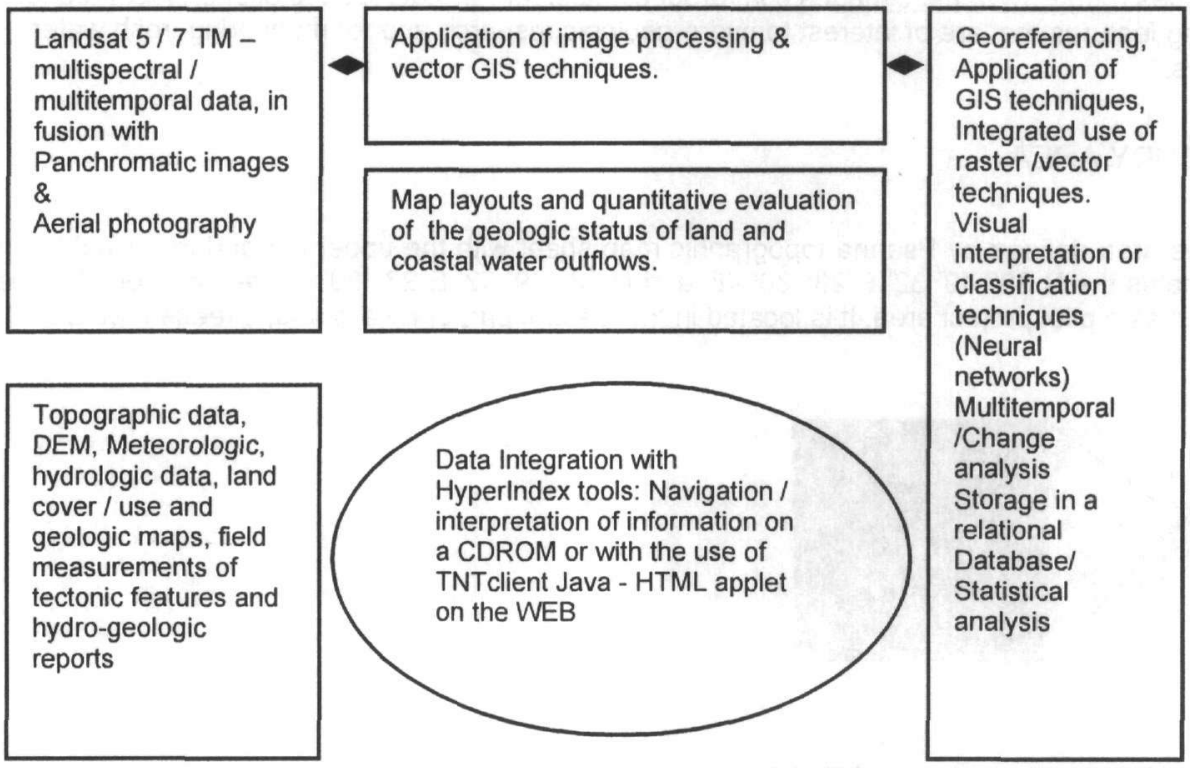

Figure 2. Overview of data and techniques that have been used in the project. 


\subsection{Satellite image data}

Three Landsat- $5 / 7$ Enhanced Thematic Mapper Plus (ETM+) scenes of Path: 183, Row: 33, have been used in the analysis, while their characteristics are described in Table 1 and Figure 2.

Table 1. Characteristics of Landsat 5 / 7 satellite systems

\begin{tabular}{|c|c|}
\hline LANDSAT $4 \& 5$ & LANDSAT 7 \\
\hline SCANNER: Thematic Mapper & SCANNER: Thematic Mapper ETM+ \\
\hline Spectral Bands & Spectral Bands \\
\hline$(\mu \mathrm{m})$ & $(\mu \mathrm{m})$ \\
\hline $1: 0.45-0.52$ & $1: 0.45-0.515$ \\
\hline $2: 0.52-0.60$ & $2: 0.525-0.605$ \\
\hline $3: 0.63-0.69$ & $3: 0.63-0.690$ \\
\hline 4:0.76-0.90 & $4: 0.75-0.90$ \\
\hline $5: 1.55-1.75$ & $5: 1.55-1.75$ \\
\hline $6: 10.40-12.50$ & $6: 10.40-12.5$ \\
\hline $7: 2.08-2.35$ & $7: 2.09-2.35$ \\
\hline & 8:.52-.90 (Panchromatic) \\
\hline SPATIAL RESOLUTION & SPATIAL RESOLUTION \\
\hline $\begin{array}{l}30 \mathrm{~m}(120 \mathrm{~m} \text { for band } 6) \\
\text { TEMPORAL RESOLUTION } 16 \text { DAYS }\end{array}$ & $\begin{array}{l}30 \mathrm{~m}(60 \mathrm{~m} \text { for band } 6)(15 \mathrm{~m} \text { for band } 8) \\
\text { TEMPORAL RESOLUTION } 16 \text { DAYS }\end{array}$ \\
\hline RADIOMETRIC RESOLUTION \& BIT & RADIOMETRIC RESOLUTION 8 BIT \\
\hline ACQUISITION DATES 26/1/1988 \& 19/1/1994 & ACQUISITION DATE 28/08/1999 \\
\hline
\end{tabular}

\section{METHOD OF ANALYSIS}

Various image processing and vector GIS techniques have been used for the analysis of both the satellite imagery and the collected map data and field information, (Table 2). The application of both image processing and vector GIS techniques has been applied using the TNTmips software package (www.microimages.com).

Table 2. Pre-processing / Image enhancement / classification

\begin{tabular}{ll}
\hline Processing technique & Description \\
\hline Georeferencing & Model: Affine \\
& \\
Resampling & Nearest Neighbour \\
Color Composites & $\begin{array}{l}\text { Applied analysis: Calculation of } 7 \star 7 \text { variance co- } \\
\text { variance matrix. Histogram contrast enhancement. } \\
\text { Application of filtering techniques. } \\
\text { Qualitative evaluation. Application of masking } \\
\text { techniques so as to separate land area from the } \\
\text { sea. The Thermal IR band is used to display the } \\
\text { sea area, using selected colour palettes of either } \\
\text { red or blue colour. }\end{array}$
\end{tabular}

Intensity Hue Saturation HIS Images

Unsupervised classification techniques (Neural networks))

Identification of Areas of Interest $\mathrm{AOI}$ concerning sea water outflows
Application of HIS transformation so as to obtain the colour synthesis of the different resolution data

Classification in a pre-defined number of classes. Editing of the classification result, interpretation of classes.

Extraction of sea water anomalies and of mean DN values for the thermal spectral band.
Result
Image map output in
Hellenic-Geodetic-
Reference System
HGRS of 1987
Image resolution of $15 \mathrm{~m}$.
Best combinations for
Landsat data are
achieved using bands TM
1,3 (or 4 ) and 5 (or 7 ) as
well as real color composites. Red color
palette displays
differences of sea
surface temperatures.
Images are enhanced while shadow is suppressed.
Interpretation of spectral characteristics of images.
Easy discrimination of land cover classes.
Estimation of sea surface temperatures and of aspects of turbidity patterns, water clarity. 
Combination of the interpretation result of multi-temporal imagery

Automatic conversion of raster to vector data.

Collection / interpretation / input / coding, Storage / Management, statistical analysis / Retrieval, Processing $/$ analysis of different data types.

Distribution of information with a free of use software on a CD or on the WEB
Qualitative estimates of temporal changes of fresh water outflows.

Inform the relational vector GIS database

Application of various vector GIS techniques. Statistical analysis of field tectonic measurements and mapped lineament on the satellite images or on the aerial photography. Output in the form of histograms or rose diagrams. Map making of the processed data.

Inform all the parties involved for the available data and temporal changes.
Raster database of temporal changes and thematic rasters

Map output

Creation of a relational database of the collected data, map making.

Presentation / Display, \&

Evaluation of temporal changes, map updating.

Contribution to hydrogeological management of the pilot project area of study

Combination of different resolution data using data fusion techniques proved to be effective as far as the land cover and the interpretation of geologic features are concerned because complementary information for the same target is combined. The Landsat ETM 7 data proved to be beneficial to the analysis due to their higher spatial resolution. The output of the classification and or interpretation process has been converted to vector data and they have been analyzed along with the map data and field observations. Three dimensional data products also facilitate the analysis. Different map outputs have been prepared for the analysis and these include those of Figure 3. Left image shows a Landsat 7 data fusion image of the R:G:B-4:5:3 spectral bands with the Panchromatic high resolution band while the thermal band is displayed with a red color palette. Water outflows are shown with the dark black color. Right image shows the 1988 scene with a true color composite for the land area overlayed by the interpretation of aerial photography and thermal band displayed with a selected color palette.

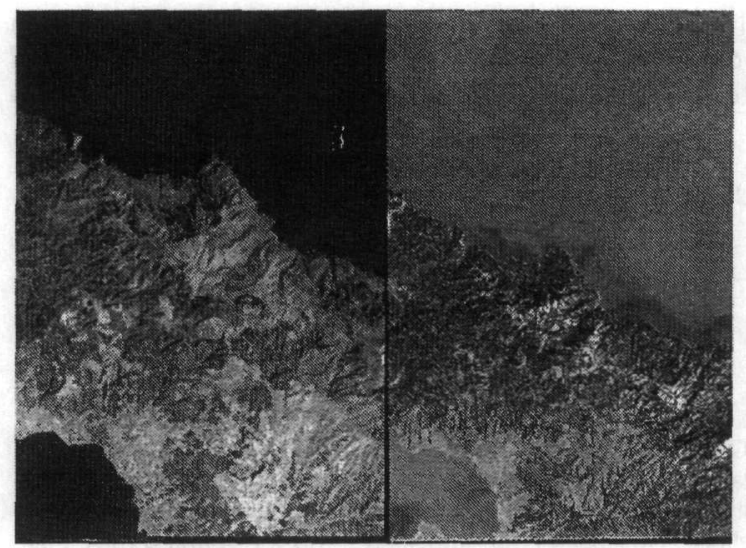

Figure 3. Left image shows a view of the Landsat 7 land/sea data product, while the right image shows the Landsat 51988 scene. Red lines show the interpreted on the aerial photography geologic features. Water outflows patterns are shown with the dark black color.

\subsection{Interpretation of geologic features and multi-temporal analysis of water outflows}

The process of temporal analysis examines the set of input raster values for the fresh water outflows, then assigns threshold values for a unique set of values and this is used to map the outflows. For each input raster with color information (stored as color palette entries), the process creates a corresponding color palette sub-object for the output raster. By analyzing the raster output the areal extent of changes in the water outflows through time are identified. To facilitate the interpretation, the area has been divided in nine different sub-areas, Figure 4. 


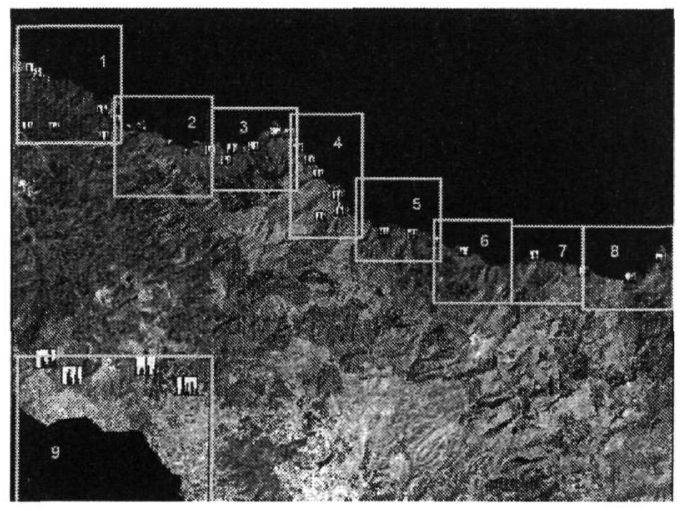

Figure 4. Yellow squares show the different sub-areas, while the field tectonic measurements are displayed in histogram form.

For each sub-area an integrated interpretation of the following data has been carried out:

1. Interpretation of water outflows on multi-temporal Landsat imagery at the three different acquisition dates $(1998,1994,1999)$.

2. Interpretation of geologic lineament patterns that have been interpreted on both the aerial photography and satellite imagery

3. Verification with faulting that it is depicted on the geological maps

4. Verification with mapped known springs

5. Acquisition of field measurements of tectonic features that have been analyzed in relation to the prevailing orientations

6. Mapping in the field of fresh water outflows that has been acquired during the summer of 1998.

7. Acquisition of field photographs of coastal features of interest to the present study (i.e outflows and geologic features).

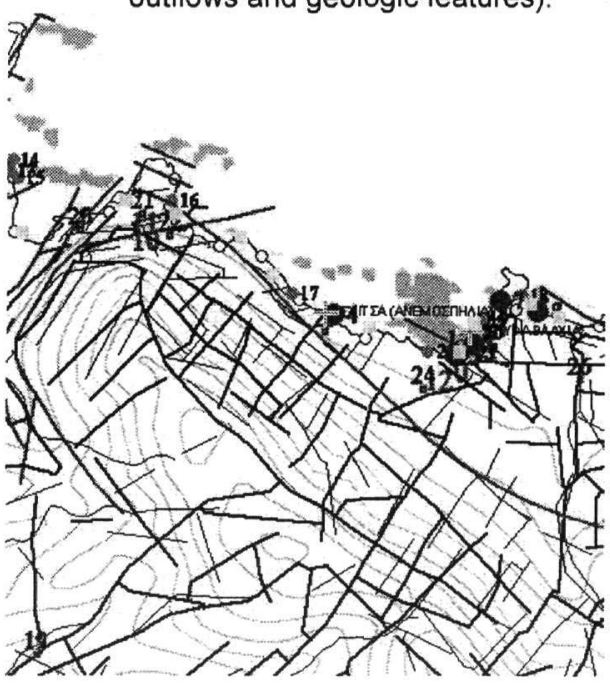
Faults
- Water outflows of '99 image
Lineaments on satellite images
Lineaments on aerial photography
Drainage metwork
Contours
Water outflows of ' 94 image
Water outflows of ' 88 image
+ Known springs
- Mapped outflows in the field
Sites of field photos
Sites of field measurements

Figure 5. Map output of sub-area 2 with $9.6 \mathrm{~km}$ long coastline and surface extend of $39 \mathrm{~km}^{2}$. 
The sub-project areas are used to display results obtained from the study as these are given in map outputs.

\subsection{Surface sea water temperatures and water outflows}

The Landsat data have been analyzed for assessing surface water temperature changes. Landsat data due to their spectral spatial and radiometric resolution are effective for an interpretation of surface water temperatures. Figures 5 and 6 show water outflows that are probably due to coastal springs.
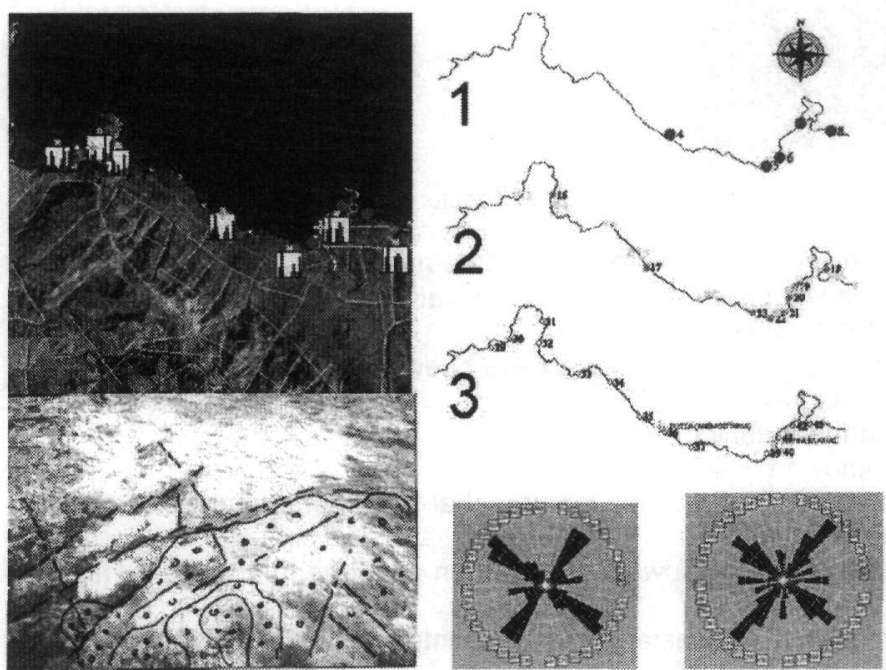

Figure 6. (Upper left) Enhanced Landsat 7 image with the interpreted lineaments. (Upper right) 1 Water outflows mapped on 1999 image, 2. water outflows mapped on 1988 and 1994 scene. (Lower left) Field photo of spring 6. (Lower right rose diagrams of interpreted features on aerial photographs and satellite image.
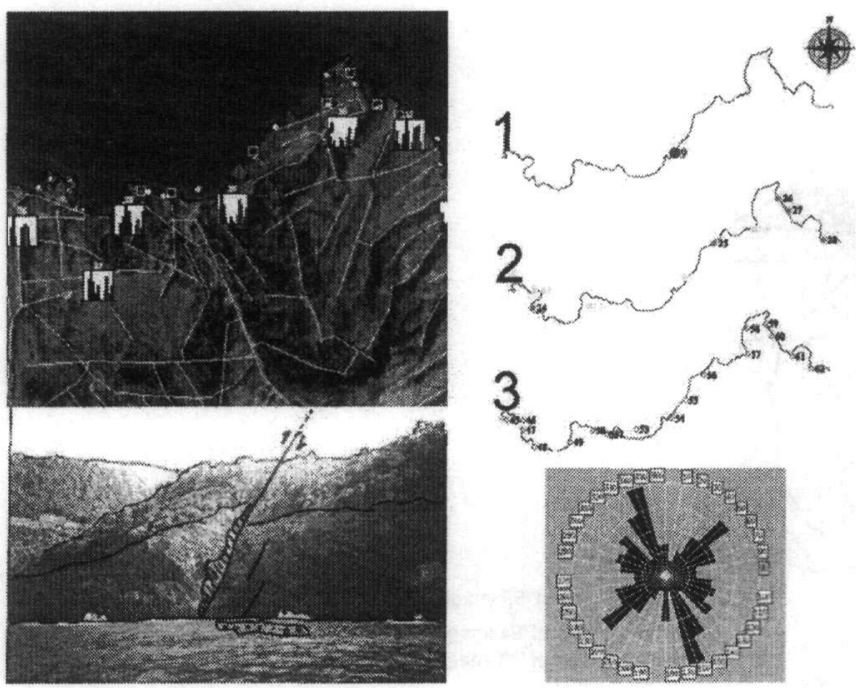

Figure 7. SUB-AREA 3: (Upper left) Enhanced Landsat 7 image with the interpreted lineaments. (Upper right) 1 Water outflows mapped on 1999 image, 2. water outflows mapped on 1988 and 1994 scene. (Lower left) Field photo of spring 9. (Lower right rose diagrams of interpreted features on the satellite images. 
Sea ground water discharge is highly variable, both in time and space. More water outflows have been interpreted on the 1988 scene. Locations vary, but certain outflows can be mapped on all three different acquisition dates.

Table 3. Change of water outflows as this is estimated from the temporal satellite images and prevailing orientations of geologic features interpreted on the satellite imagery and aerial photography

\begin{tabular}{|c|c|c|c|c|c|c|}
\hline No & $\begin{array}{l}\text { Prevailing } \\
\text { orientations } \\
\text { Satellite imagery / } \\
\text { Aerial } \\
\text { photography }\end{array}$ & $\begin{array}{l}\text { LANDSAT } \\
1988 \\
\text { Number } \\
\text { of } \\
\text { outflows }\end{array}$ & $\begin{array}{l}\text { LANDSAT } \\
1994 \\
\text { Number of } \\
\text { outflows }\end{array}$ & $\begin{array}{l}\text { LANDSAT } \\
1999 \\
\text { Number } \\
\text { of } \\
\text { outflows }\end{array}$ & $\begin{array}{l}\text { KNOWN } \\
\text { SPRINGS }\end{array}$ & $\begin{array}{l}\text { MAPPED } \\
\text { OUTFLOWS } \\
\text { (In the field) }\end{array}$ \\
\hline 1 & $\begin{array}{l}\text { NE-SWI } \\
\text { NE.E-SW.W }\end{array}$ & 12 & 5 & 3 & 1 & 27 \\
\hline 2 & $\begin{array}{l}\text { NE-SE I } \\
\text { SE-NE }\end{array}$ & 10 & 10 & 5 & 2 & 15 \\
\hline 3 & $\begin{array}{l}\text { E-N.NW I } \\
\text { N.NW-NE }\end{array}$ & 5 & 4 & 1 & & 18 \\
\hline 4 & $\begin{array}{l}\text { NE I } \\
\text { NE-NW }\end{array}$ & 9 & 11 & 6 & & 17 \\
\hline 5 & $\begin{array}{l}\text { N.NW-N.NE I } \\
\text { NE-SW }\end{array}$ & 3 & 4 & 4 & & 14 \\
\hline 6 & $\begin{array}{l}\text { NE-E.W/ } \\
\text { N.NW-NE }\end{array}$ & 7 & 4 & 7 & & 10 \\
\hline 7 & $\begin{array}{l}\text { NE-N.NW I } \\
\text { N.NE-N.NW }\end{array}$ & 3 & 2 & 3 & & 18 \\
\hline 8 & $\begin{array}{l}\text { N.S-E.NEI } \\
\text { NE.NNW }\end{array}$ & 5 & 5 & 4 & & 15 \\
\hline 9 & $\begin{array}{l}\text { NE-E.NWI } \\
\text { N.NW-NE }\end{array}$ & 6 & 5 & & 2 & \\
\hline TOTAL & & 61 & 49 & 33 & 5 & 158 \\
\hline
\end{tabular}

A fluctuation of the water outflows can be interpreted on the satellite images and this has been attributed to both seasonal and yearly variations of the hydrologic regime of the area. The first two Landsat images have been acquired during January that is one month later than December which is the wettest month for the pilot project area, while the third one during August which is the month that follows the dry period of the year with the minimum amount of rainfall. Known Springs have been identified on the multi-temporal satellite imagery. More springs have been mapped on the satellite imagery than the already known springs and the ratio varies between 6.6 for the dry period of year 1999 or 12.2 for the wet period of year 1988 and the known springs. The location of the mapped on the satellite imagery water outflows has been confirmed in the field, while more outflows can be identified in the field. This is probably due to the karstic terrain that prevails in the area.

The project has resulted in multiple data that could be useful to different local authorities that are responsible for the hydrologic management of the area. All data have been organized in a form of an informational Atlas which can then be distributed in the form of a CD or on the WEB using the TNT software products. TNT atlas software is a free product for viewing hierarchical atlases prepared in TNTmips with Hyper Index Linker or for single layout atlases. Different layouts have been organized one for the total area of the pilot project area and the nine sub-areas. With the use of TNT atlas, all data can be distributed on a CD and take advantage of its low media cost, small physical size, permanence of media, and quick access to large collections of geospatial data to the involved parties in the hydrologic management of the project area. With TNT atlas, even computer users who have little training can easily access the organized geospatial information concerning the study area. And finally all data can be used in any kind of computer the end-users are using. The objects and views in the electronic atlas can be complex while various processing techniques can be applied. 


\section{CONCLUSION}

Remote sensing provides valuable information concerning different parameters of interest to a hydrological project. Differences in the density of the measured number of water outflows between the various satellite image data are attributed to different acquisition dates and different amount of rainfall of the previous years. The locations of water outflows are related to the faulting system of the tectonic discontinuities that prevail in the main tectonic blocks. These discontinuities are used as conduits for the subsurface water flow. The large density differences that are observed between the outflows that have been recorded in the field and those interpreted on the satellite images are due to the image resolution of the thermal bands and the prevailing hydrological conditions during the previous year than the one when the field campaign has been carried out. New satellite image products of improved spectral, spatial and radiometric resolution can give better results related to the identification of water outflows. These results can be used for a statistical estimate of hydrologic balance of the coastal hydrologic river basins.

Monitoring is supported due to the multi-temporal character of the data. Additionally, satellite data can be analysed to generate GIS database information required for hydrological studies. Generated database can be used to assess changes that are taking place for the fresh water outflows in coastal areas while tectonic features can be mapped effectively. The added advantage of the proposed approach is that it makes available to end-users a variety of the data and that it helps in efficient analysis and prediction. An advantage of using remote sensing is that data for large areas within a single image can be collected quickly and relatively inexpensively, while this can be repeated through selected time intervals. In addition, satellite techniques are very capable of supplementing the inter-comparison experiments by providing additional geographic information about the setting. It is clear that in order to make regional assessments, one must develop a means to extrapolate from well-studied areas, as the sites of our inter-comparisons, to other coastlines. Since the strength of satellite imagery for SGD monitoring is the regional scale dimension, more than one location has to be taken for reference in order to learn how to separate SGD- related anomalies from all kinds of important interfering phenomena. Finally, the Atlas offers an intuitive, self-paced, and self-contained way to provide secure public viewing of data such as multi-temporal information provided by satellite systems, land cover / use, and available hydrologic / hydrogeologic environmental information.

\section{REFERENCES}

Antoine, D., J.-M. Andre, and A. Morel, 1996. Oceanic primary production - 2. Estimation at global scale from satellite (coastal zone color scanner) chlorophyll. Global Biogeochemical Cycles 10(1), 57-69.

Astaras, Th., Oikonomidis D., 2002. Identification-Delineation of regions of fresh water outflow and saline coastal zones using Landsat 5/TM images. Proceedings of the $6^{\text {th }}$ Pan-Hellenic Hydrogeological Conference. Xanthi 8-10 November 2002 pp 337-346.

Batelaan, O., F. DeSmedt, P. DeBecker, and W. Huybrechts, 1998. Characterization of a regional groundwater discharge area by combined analysis of hydrochemistry, remote sensing and groundwater modeling. In: Dillon, P., Simmers, I. (eds) Shallow groundwater systems. International Contributions to Hydrogeology 18, 75-86.

Buddemeier, R.W. (ed.), 1996. Groundwater Discharge in the Coastal Zone: Proceedings of an International Symposium. LOICZ/R\&S/96-8, iv+179 pp. LOICZ, Texel, The Netherlands.

Garrity, C., 1991. Passive microwave remote sensing of snow covered floating ice during spring conditions in the Arctic and Antarctic. Diss. York Univ., Toronto, $348 \mathrm{p}$.

HAGS - Hellenic Army Geographic Service, 1977 Psahna 1:100,000 Scale Map Sheet

HAGS - Hellenic Army Geographic Service, Aerial Photography 1967

Hanslow, D.J., B. Clout, P. Evans, B. Coates, 1997. Monitoring coastal change using photogrammetry. In: Bliss, E. (ed) Islands; economy, society and environment. New Zealand Geographical Society Conference Series $19,422-426$.

Howarth, P.J., T.T. Alfoeldi, P. Laframboise, J.C. Munday, K.P.P. Thompson, G.F. Tomlins, and G.M. Wickware, 1982. Landsat for monitoring hydrologic and coastal change in Canada. In: Thompson, M.D. (ed.) Landsat for monitoring the changing geography of Canada. Can. Cent. Remote Sensing, Energy, Mines and Resour.. Ottawa, ON, Canada, 7-40.

Katsikatsos G. et. al, 1981 Psachna -Pilion Geologic Map Sheet of !:50,000 scale, Published by Publication

Department of Geological Maps of IGME.

Kohout, F.A., 1966. Submarine Springs: A neglected phenomenon of coastal hydrology. Hydrology, 26, $391-$ 413. 
Massom, R.A., J.C. Comiso, A.P. Worby, V.I. Lytle, L. Stock, 1999. Regional classes of sea ice cover in the East Antarctic Pack observed from satellite and in situ data during a winter time period. Remote Sensing of Environment 68(1), 61-76.

Moore, W., 1996. Large groundwater inputs to coastal waters revealed by $226 R$ a enrichments. Nature, 380 , 612-614.

Schweitzer, P.N., 1993. Modern average global sea-surface temperature. US Geological Survey Digital Data Series, CD-ROM.

Stefouli M., Tsombos P., 2002. Spatio-temporal analysis of morpho-tectonic parameters using integrated image processing / GIS techniques - Pilot project of Vegoritida lake. Proceedings of the $6^{\text {th }}$ Pan-Hellenic Geographical Conference of the Hellenic Geographical Society. Thessaloniki, 3-6 October 2002 pp 248256.

Tsombos P.I. (1995). Location of ground water outflows in costal and near costal areas using remote sensing techniques. POSTER in the 3th Hydrogeological meeting of the geological society of Greece in Iraklio Krete, Greece, 3-5 Nov.1995.

Tsombos P.I. et all (1999). The use of Remote Sensing techniques, in the ground water exploration of granite areas. The example of Sithonia Peninsula, N. Greece. 5th Hydrogeological meeting of the geological society of Greece in Levkosia, Cyprus 12 - 14 November 1999.

Utzmann, S.J., L.M. Cathles, and W.D. Philipot, 1989. Combined Landsat imagery and raster based geophysics as an exploration tool. Proceedings of the Thematic Conference on Geologic Remote Sensing 7, 12591267.

Valiela, I. and C.D'Elia, 1990. Groundwater inputs to coastal waters. Special Issue Biogeochemistry, 10, $328 \mathrm{p}$. 